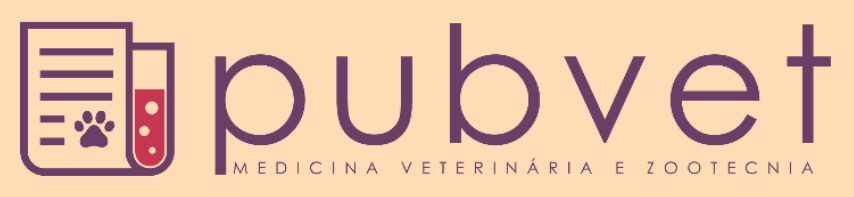

ISSN $1982-1263$

https://doi.org/10.31533/pubvet.v13n4a302.1-6

\title{
Sinais clínicos apresentados por cães positivos para leishmaniose visceral no município de Vassouras, Rio de Janeiro
}

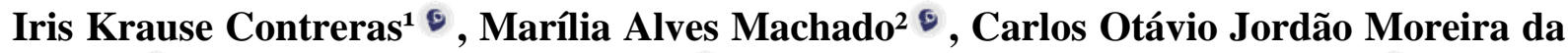 \\ Rocha $^{3 \oplus}$, Glenda Ribeiro de Oliveira ${ }^{4}$, Flávia Clare Goulart de Carvalho ${ }^{* 0} \bullet$ \\ ${ }^{1}$ Discente da Universidade de Vassouras, Vassouras, Rio de Janeiro, Brasil \\ ${ }^{2}$ MV , Doutoranda do Programa de Pós-Graduação em Ciências Veterinárias da Universidade Federal Rural do Rio de \\ Janeiro, Seropédica, Rio de Janeiro, Brasil \\ ${ }^{3} \mathrm{MV}$, clínica veterinária SOS animal, Vassouras, Rio de Janeiro, Brasil \\ ${ }^{4}$ Docente da Universidade de Vassouras, Vassouras, Rio de Janeiro, Brasil \\ ${ }^{5}$ Doutora, Prof. ${ }^{a}$ de Pós-graduação em dermatologia no Equalis, SP, MV na clínica SOS animal, Vassouras, RJ, Brasil, \\ * Autor para correspondência, Tel:(24)992727478 e E-mail: flaviaclare@ gmail.com
}

Resumo. Atualmente, novos casos de leishmaniose visceral estão sendo relatados de forma significativa, como uma importante questão de saúde pública. Essa zoonose provocada pelo protozoário Leishmania spp., é transmitida principalmente pelo flebotomíneo Lutzomyia longipalpis acometendo diversas espécies de mamíferos, sendo o cão doméstico o principal mantenedor do agente em áreas urbanas. A inespecificidade de sinais clínicos, associada à elevada casuística na espécie promove difícil controle da transmissão, diagnóstico e tratamento da doença. Assim, objetivou-se avaliar a sintomatologia apresentada por seis cães positivos para leishmaniose visceral, no município de Vassouras. A investigação retrospectiva foi realizada pelo apontamento das informações presentes nas fichas clínicas de cada animal, seguido de análise estatística descritiva. Os sinais clínicos mais relevantes incluíram anemia, hepatomegalia, icterícia e seborreia. As regiões mais acometidas foram membros, coxins, plano nasal e orelhas. A comparação da sintomatologia em diferentes casos auxilia na compreensão da doença, além de agregar possíveis diagnósticos diferenciais, proporcionando melhor qualidade na investigação clínica ao paciente.

Palavras-chave: dermatopatias, leishmania spp., zoonose

\section{Clinical signs presented by Leishmania positive dogs in the city of Vassouras-RJ}

Abstract. Currently, the scope of areas affected by leishmaniasis has been growing
significantly, being an important matter of public and animal health. This zoonotic disease
caused by the Protozoan Leishmania spp., is transmitted primarily by the bite of sandflies,
affecting various species of mammals, and the domestic dog the main maintainer of the
agent in urban areas. The low specificity of clinical signs associated with high
assintomatology in species, promote hard transmission control, diagnosis and treatment of
this disease. Therefore, the objective of assessing the symptoms presented by six dogs
positive for leishmaniasis, in the municipality of Vassouras. The investigation was
conducted by the retrospective appointment of the information present in the charts of each
animal, followed by descriptive statistical analysis. Relevant symptoms included anaemia,
hepatomegaly, jaundice, linfonodomegalia, onychogryphosis, alopecia, crusted lesions,
peeling, hyperkeratosis and seborrhea. The regions most affected were members, cushions,
nose and ears. The comparison of symptoms in different cases assists in understanding the 
disease, in addition to add possible differential diagnosis, providing better quality of life for patients.

Keywords: Leishmaniasis; symptomatology; dermatopatia; dogs

\title{
Signos clínicos presentados por perros positivos para leishmaniasis visceral en el municipio de Vassouras, Rio de Janeiro
}

\begin{abstract}
Resumen. Actualmente, nuevos casos de leishmaniasis visceral se están reportando de forma significativa, como una importante cuestión de salud pública. Esta zoonosis provocada por el protozoario Leishmania spp., Es transmitida principalmente por el flebotomíneo Lutzomyia longipalpis que afecta a diversas especies de mamíferos, siendo el perro doméstico el principal mantenedor del agente en áreas urbanas. La inespecificidad de signos clínicos, asociada a la elevada casuística en la especie, promueven difícil control de la transmisión, diagnóstico y tratamiento de la enfermedad. Siendo así, se objetivó evaluar la sintomatología presentada por seis perros positivos para leishmaniosis visceral, en el municipio de Vassouras. La investigación retrospectiva fue realizada por el apunte de las informaciones presentes en las fichas clínicas de cada animal, seguido de análisis estadístico descriptivo. Los signos clínicos más relevantes incluyeron anemia, hepatomegalia, ictericia y seborrea. Las regiones más acometidas fueron miembros, cojines, plano nasal y orejas. La comparación de la sintomatología en diferentes casos auxilia en la comprensión de la enfermedad, además de agregar posibles diagnósticos diferenciales, proporcionando mejor calidad en la investigación clínica al paciente.
\end{abstract}

Palabras clave: dermopatías, leishmania spp., Zoonosis

\section{Introdução}

A leishmaniose é uma zoonose cosmopolita provocada por protozoários intracelulares do gênero Leishmania spp., e seu principal vetor é o flebotomíneo hematófago Lutzomyia longipalpis (Gontijo et al., 2011). Aproximadamente 70 espécies de mamíferos, incluindo os seres humanos são considerados hospedeiros vertebrados de diferentes espécies deste parasito pelo mundo. O cão doméstico (Canis familiaris) é seu principal reservatório em áreas urbanas e periurbanas, sendo a infecção de cães normalmente precedente a ocorrência de casos em humanos (França-Silva et al., 2005).

Os sinais clínicos são inespecíficos e podem incluir linfadenomegalia, alopecia, atrofia muscular e condição corporal comprometida, além de hiporexia, onicogrifose, anemia, alterações oftálmicas, cardíacas e neurológicas (Dantas-Torres et al., 2012; Feitosa et al., 2000; Wilson et al., 2012). Atualmente, o diagnóstico pode ser obtido por meio de associação de alguns testes como: imunocromatográfico, RIFI e ELISA para triagem e acompanhamento (Dantas-Torres et al., 2017; Gontijo et al., 2011), o PCR e Parasitológico como confirmatório (Dantas-Torres et al., 2017; DantasTorres et al., 2012). É necessário determinar o estágio clínico da doença em que o animal se encontra. O protocolo terapêutico é base da mitelfosina, medicamento que realiza alterações na membrana plasmática do parasita, além de ocasionar apoptose durante a fase promastigota (Gontijo et al., 2011), no entanto, existem outros fármacos devem ser associados ao tratamento como o alopurinol, antimoniato de meglumina, domperidora, corticosteroides e imunoterapia, bem como uso de coleiras repelentes para evitar o vetor, e outra opção seria a imunoterapia (Gontijo et al., 2011).

A dificuldade na identificação da patologia se dá principalmente pela inespecificidade de sinais clínicos, associada ao alto índice de assintomatologia na espécie, por isso, objetivou-se analisar os sinais clínicos apresentados pelos cães atendidos com o diagnóstico de leishmaniose visceral, com objetivo de buscar possíveis paradigmas a respeito da doença.

\section{Material e métodos}

Foi realizado um levantamento retrospectivo da casuística apresentada por seis cães, atendidos no Hospital Veterinário da Universidade de Vassouras e na Clínica Veterinária SOS Animal, diagnosticados com leishmaniose visceral no município de Vassouras, Rio de Janeiro, de forma aleatória 
e isolada, pelas fichas de atendimentos clínicos, preenchidas pelo médico veterinário responsável pela consulta. Na ficha de atendimento clínico constavam informações a respeito do histórico, anamnese, exames físicos, laboratoriais, diagnóstico, tratamento e acompanhamento do paciente. Além disso, uma parte destinada às dermatopatias apresentadas pelo animal e suas localizações. Após o levantamento das fichas, os dados clínicos colhidos foram adicionados a uma tabela, separando as sintomatologias apresentadas em sistêmica e dermatológica, assim como suas localizações. Pela estatística descritiva simples por regra de três, obtiveram-se as porcentagens de cada sinal clínico, observando-se, assim, a relevância de cada um e sua maior prevalência no grupo de estudo. Os resultados foram então discutidos com a literatura disponível.

\section{Resultados}

A partir da análise do grupo de estudo, observou-se que os seis animais (100\%) manifestaram dermatopatias dentre a sintomatologia da leishmaniose (Tabela 1). Dentro das afecções sistêmicas, 50\% dos cães exibiram perda de peso, 33,3\% apontaram linfadenomegalia, e 16,6\% apresentaram anemia, hepatomegalia, esplenomegalia, icterícia e onicogrifose, como demonstrado na Tabela 1. Observe-se que essa porcentagem corresponde, respectivamente, a dois cães no primeiro caso $(33,3 \%)$ e a um cão no segundo caso $(16,6 \%)$, sendo que não necessariamente o mesmo animal apresentou essa sintomatologia simultaneamente.

Tabela 1. Sintomatologia sistêmica encontrada nos animais estudados

\begin{tabular}{ll}
\hline & Sintomatologia sistêmica \\
\hline Emagrecimento & $50,00 \%$ \\
Linfadenomegalia & $33,30 \%$ \\
Anemia & $16,60 \%$ \\
Hepatomegalia & $16,60 \%$ \\
Esplenomegalia & $16,60 \%$ \\
Icterícia & $16,60 \%$ \\
Onicogrifose & $16,60 \%$ \\
\hline
\end{tabular}

Dentro das afecções dermatológicas, 83,3\% apresentaram alopecia; 50\% demonstraram lesões crostosas, descamação, hiperqueratose e seborreia; 33,3\% relataram colarete, demodicose associada, escoriação, úlceras, erosão e prurido; e 16,6\% desenvolveram eritema, pústulas, pápulas, descamação prateada, hipotricose, foliculite, furunculose, nodulações e lesões hemorrágicas, como pode ser observado na Tabela 2.

Tabela 2. Dermatopatias apresentadas pelos cães do estudo.

\begin{tabular}{lr}
\hline & Sintomatologia dermatológica \\
\hline Alopecia & $83,30 \%$ \\
Crostas & $50,00 \%$ \\
Descamação & $50,00 \%$ \\
Hiperqueratose & $50,00 \%$ \\
Seborréia & $50,00 \%$ \\
Colarete & $33,30 \%$ \\
Demodicose & $33,30 \%$ \\
Escoriação & $33,30 \%$ \\
Erosão & $33,30 \%$ \\
Prurido & $33,30 \%$ \\
Úlcera & $33,30 \%$ \\
Descamação prata & $16,60 \%$ \\
Eritema & $16,60 \%$ \\
Foliculite & $16,60 \%$ \\
Furunculose & $16,60 \%$ \\
Pápula & $16,60 \%$ \\
Pústula & $16,60 \%$ \\
Hipotricose & $16,60 \%$ \\
Nodulações & $16,60 \%$ \\
Lesões hemorrágicas & $16,60 \%$ \\
\hline
\end{tabular}


A localização das lesões caracterizou-se por 50\% de lesões em orelhas, cabeça e tronco; 33,3\% em plano nasal, região periorbital, membros e coxins; e 16,6\% em pênis e região ingnal, demonstrado na Tabela 3.

Tabela 3. Localização das dermatopatias apresentadas pelos cães do estudo

\begin{tabular}{lc}
\hline & Localização das dermatopatias \\
\hline Orelhas & $50,00 \%$ \\
Cabeça & $50,00 \%$ \\
Tronco & $50,00 \%$ \\
Plano nasal & $33,30 \%$ \\
Região periorbital & $33,3 \%$ \\
Membros & $33,30 \%$ \\
Coxins & $33,30 \%$ \\
Pênis & $16,60 \%$ \\
Região ingnal & $16,60 \%$ \\
\hline
\end{tabular}

O cão número 1, apresentou leve icterícia, adenite generalizada, emagrecimento progressivo, descamação cutânea furfurácea, lesões crostosas e ulceradas em ponta de orelha, lesão crostosa em plano nasal e na região periorbital, bem como lesão circular e crostosa no membro posterior direito; o cão número 2, apresentou quadro clínico dermatológico com alopecia generalizada, dermatite descamativa, foliculite, furunculose, demodiciose, hiperqueratose no plano nasal e coxins plantares, onicogrifose (Figura1), hepatomegalia, esplenomegalia e anemia; o cão número 3, apresentou conjuntivite (Figura 2), edema palpebral, prurido, lesões eritematosas, erosivas, alopecicas e crostosas colarete, hipotricose em cabeça, pescoço e abdome ventral, hiperqueratose, seborreia, demodiciose e lesão ulcerada em ponta de orelha (Figura 3). Além disso, exibia diversos nódulos cutâneos ao longo do tronco, acompanhado de paniculite; o cão número 4 apresentou linfadenomegalia e lesões alopécicas na face, escápula, peito e membros anteriores e posteriores; o cão número 5 apresentava descamação, lesão alopécica atrás das orelhas, pústulas na região ingnal, seborreia no dorso e lesões hemorrágicas em coxim e pênis; o cão número 6 apresentou perda de peso (Figura 4), edema em membros, lesões não cicatrizantes alopécicas, ulceradas e crostosas, com colarete, pápula, seborreia, descamações prateadas em orelhas e tronco, hiperqueratose e demodiciose.

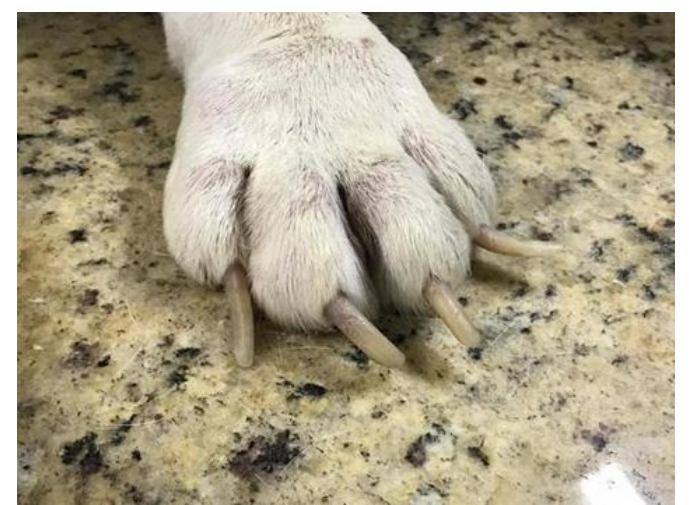

Figura 1. Onicogrifose

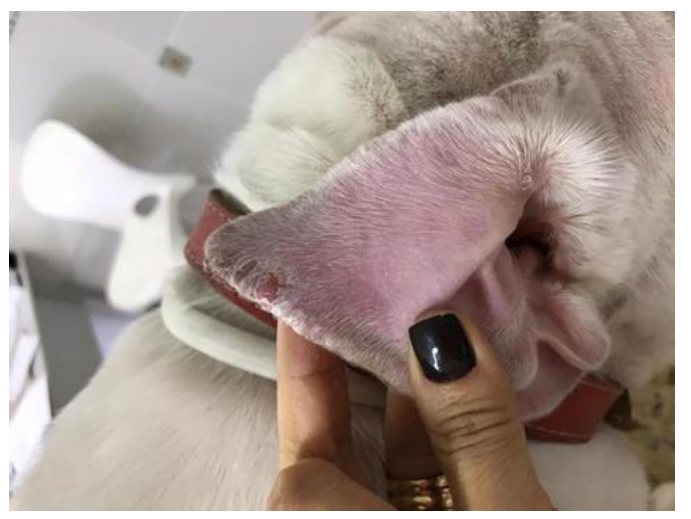

Figura 3. Lesão em ponta de orelha

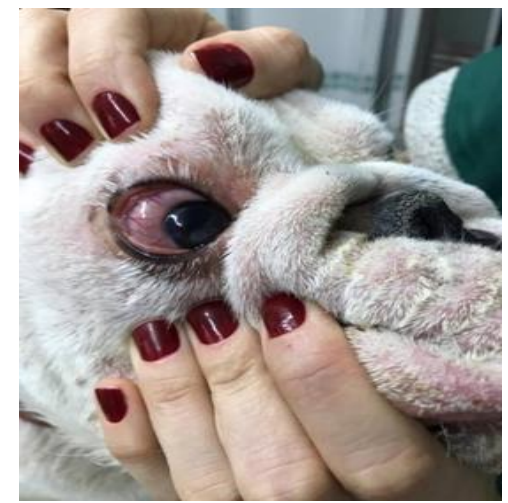

Figura 2. Afecções oftálmicas e na face

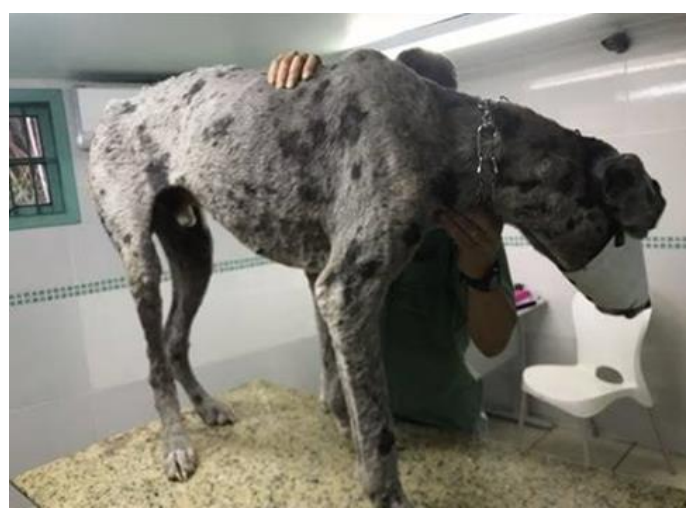

Figura 4. Dermatopatias presentes no corpo do animal 


\section{Discussão}

A sintomatologia, muitas vezes inespecífica, torna o diagnóstico de difícil precisão, uma vez que sofre interferência de diversos fatores como o hospedeiro, vetor e parasito, e está diretamente relacionada ao grau de infecção (Dantas-Torres et al., 2012). A manifestação pode ser de forma branda, oligossintomática ou de forma grave, polissintomática (Dantas-Torres \& Brandão-Filho, 2006; Wilson et al., 2012). A maioria dos animais apresentam linfadenomegalia, alopecia, atrofia muscular e condição corporal comprometida (Dantas-Torres et al., 2012). São descritos sinais clínicos gerais como linfadenomegalia (em $81 \%$ dos casos), hiporexia (58\%), onicogrifose $(51 \%)$ e emaciação $(47 \%)$. A anemia é um achado clínico consistente em 30\% dos animais com leishmaniose, além de emagrecimento, hipertermia, diarreia, melena e pneumonia (Feitosa et al., 2000). Alterações oftálmicas são comuns dentre as manifestações clínicas desta doença, caracterizadas principalmente por uveíte, edema uveal, corneano e miose (Feitosa et al., 2000; Koutinas \& Koutinas, 2014).

A sintomatologia sistêmica manifestada no presente trabalho coincide com achados nos estudos de Wilson et al. (2012) e Koutinas \& Koutinas (2014), como esplenomegalia (16,6\%), hepatomegalia $(16,6 \%)$, anemia $(33,3 \%)$, linfadenomegalia $(33,3 \%)$, alterações oftálmicas $(33,3 \%)$ e emagrecimento (50\%), como relatado por Feitosa et al. (2000). No entanto, esplenomegalia, alterações locomotoras, comprometimento articular por deposição de imunocomplexos, cardíacas, neurológicas e comprometimento urinário como descritos nos estudos de Feitosa et al. (2000), Wilson et al. (2012) e Koutinas \& Koutinas (2014) não foram apresentadas nos animais avaliados.

Os animais podem apresentar ortoceratose, crostas, edemas, hiperplasia epidermal, dermatites perivascular, intersticial e nodular, perifoliculites, adenite sebácea e paniculites, úlceras, nódulos, pústulas e pápulas, corroborando com Saridomichelakis (2009), Papadogiannakis et al. (2005) e Saridomichelakis et al. (2007). Alterações cutâneas como lesões ulceradas, crostosas, foliculite, dermatite seborreica, alopecia, onicogrifose e hiperqueratose ${ }^{5}$ encontradas no presente estudo corroboram com a literatura, podendo-se observar uma ligeira repetição em determinados sinais clínicos (Saridomichelakis \& Koutinas, 2014; Wilson et al., 2012). A localização das lesões incluiu as regiões da cabeça, plano nasal, região periorbital, orelhas, tronco, membros, coxins, região ingnal e pênis, sendo compatível com estudos, onde eram principalmente localizadas nas orelhas, na bolsa escrotal e no focinho, sendo, na maior parte, lesões únicas, ulceradas ou úlcero-crostosas e de evolução crônica (Madeira et al., 2003).

Apesar da ausência de sinais patognomônicos na leishmaniose, a prevalência dos sintomas clínicos no presente estudo foi similar a relatos apresentados por outros pesquisadores. No entanto, a relevância percentual de cada manifestação é variável, devido a diferentes materiais e métodos e quantidade de animais nos estudos.

\section{Considerações finais}

Apesar de constantes descobertas sobre a leishmaniose visceral, a ausência de sinais patognomônicos institui um difícil diagnóstico e com isso um tratamento postergado. Logo, faz-se necessária a avaliação geral e minuciosa do paciente, com atenção às particularidades descritas, que podem direcionar à possível suspeição do diagnóstico e solicitação de exames confirmatórios, tratamentos adequados, melhora da qualidade de vida dos pacientes e associado ao controle em saúde pública.

\section{Referências bibliográficas}

Dantas-Torres, F. \& Brandão-Filho, S. P. (2006). Expansão geográfica da leishmaniose visceral no Estado de Pernambuco. Revista da Sociedade Brasileira de Medicina Tropical, 39(4):352-356.

Dantas-Torres, F., Sales, K. G. S., Silva, L. G., Otranto, D. \& Figueredo, L. A. (2017). LeishmaniaFAST15: a rapid, sensitive and low-cost real-time PCR assay for the detection of Leishmania infantum and Leishmania braziliensis kinetoplast DNA in canine blood samples. Molecular and Cellular Probes, 3165-69.

Dantas-Torres, F., Solano-Gallego, L., Baneth, G., Ribeiro, V. M., Paiva-Cavalcanti, M. \& Otranto, D. (2012). Canine leishmaniosis in the Old and New Worlds: unveiled similarities and differences. Trends in Parasitology, 28(12):531-538. 
Feitosa, M. M., Ikeda, F. A., Luvizotto, M. C. R. \& Perri, S. H. V. (2000). Clinical aspects of dogs with visceral leishmaniasis from Araçatuba-São Paulo State (Brazil). Clínica Veterinária, 5(28):36-44.

França-Silva, J. C., Barata, R. A., Costa, R. T., Monteiro, E. M., Machado-Coelho, G. L. L., Vieira, E. P., Fortes-Dias, C. L. (2005). Importance of Lutzomyia longipalpis in the dynamics of transmission of canine visceral leishmaniasis in the endemic area of Porteirinha Municipality, Minas Gerais, Brazil. Veterinary Parasitology, 131(3-4):213-220.

Gontijo, B. B., Pavão, F. F., Silva, F. S. A., Silva, F. D., Tavares, G. C. \& Coelho, G. L. (2011). Esporotricose e Leishmaniose Tegumentar em cães e gatos: semelhanças e diferenças. PUBVET, 51245-1250.

Koutinas, A. F. \& Koutinas, C. K. (2014). Pathologic mechanisms underlying the clinical findings in canine leishmaniosis due to Leishmania infantum/chagasi. Veterinary Pathology, 51(2):527-538.

Madeira, M. F., Uchôa, C. M. A., Leal, C. A., Silva, R. M. M., Duarte, R., Magalhães, C. M. \& Serra, C. M. B. (2003). Leishmania (Viannia) braziliensis in naturally infected dogs. Revista da Sociedade Brasileira de Medicina Tropical, 36(5):551-555.

Papadogiannakis, E. I., Koutinas, A. F., Saridomichelakis, M. N., Vlemmas, J., Lekkas, S., Karameris, A. \& Fytianou, A. (2005). Cellular immunophenotyping of exfoliative dermatitis in canine leishmaniosis (Leishmania infantum). Veterinary Immunology and Immunopathology, 104(3-4):227237.

Saridomichelakis, M. N. (2009). Advances in the pathogenesis of canine leishmaniosis: epidemiologic and diagnostic implications. Veterinary Dermatology, 20(5-6):471-489.

Saridomichelakis, M. N. \& Koutinas, A. F. (2014). Cutaneous involvement in canine leishmaniosis due to L eishmania infantum (s yn. L. chagasi). Veterinary Dermatology, 25(2):61-e22.

Saridomichelakis, M. N., Koutinas, A. F., Olivry, T., Dunston, S. M., Farmaki, R., Koutinas, C. K. \& Petanides, T. (2007). Regional parasite density in the skin of dogs with symptomatic canine leishmaniosis. Veterinary Dermatology, 18(4):227-233.

Wilson, T. M., Magalhães, L. F., Medeiros, A. A. \& Furquim, M. E. C. (2012). Alterações macroscopicas em cães sororreagentes para Leishmania chagasi e sua correlação com teste parasitologico. Veterinária Notícias Veterinary News, 18(2):20-25.

\footnotetext{
Recebido: 27 de fevereiro, 2019.

Aprovado: 1 de março, 2019.

Publicado: 12 de abril, 2019
}

Licenciamento: Este artigo é publicado na modalidade Acesso Aberto sob a licença Creative Commons Atribuição 4.0 (CC-BY 4.0), a qual permite uso irrestrito, distribuição, reprodução em qualquer meio, desde que o autor e a fonte sejam devidamente creditados 